\title{
New Philosophy of Plural World, New Ethics of Empathy
}

\author{
Alexander Tetior \\ Moscow State University of Environmental Engineering, Moscow, Russia \\ Email: atetior@mail.ru
}

Received 27 December 2014; accepted 15 January 2015; published 21 January 2015

Copyright (C) 2015 by author and OALib.

This work is licensed under the Creative Commons Attribution International License (CC BY). http://creativecommons.org/licenses/by/4.0/

(c) (i) Open Access

\section{Abstract}

The philosophy of binary plurality of the World with its branching evolution and converging devolution is the most general concept of Universe, doctrine about life. It is knowledge of binary plurality of subjects and of phenomena joining in different parities dual multitude of opposite qualities existing with branching and convergences World. The philosophy of binary plurality of the World with its branching evolution and with converging devolution may promote explanation of an opportunity of more objective interaction of the person with the World [1]-[3]. New ecological ethics of empathy may conform to new philosophy: it takes into account the plurality of all subjects and phenomenon. Author proposes new ecological ethics of empathy to life of nature, of understanding (from position of human life) all complexity and difficulty of life of animate organisms in nature [4]. Ethics of empathy do not demand love to all creations of wildlife; it does not demand reverence for all forms of life. This ethics supposes deep understanding of their indispensability and necessity. All living organisms, all forms of life are necessary and invaluable for nature; they cannot be replaced with other organisms. They do not demand creation for them more favorable, comfort and sparing conditions of life. This ethics is the most real ethics.

\section{Keywords}

Philosophy of Plurality, Ethics of Empathy, Branching Evolution, Converging Devolution, Plurality of Universe

Subject Areas: Education, Philosophy, Sociology

\section{Introduction}

New philosophy conforms partially to ancient myths, to some of positions of Daoism and of dialectics [1]. Basis of this philosophy is prospective laws of the binary plurality, of branching development and of convergence, and of dynamical integrity of branching development and convergence as bases of existence of the World. The new 
philosophy is based on some provisions of the dialectic, Taoism, ancient mythology. A basis of life is development with a branching, with growth of plurality and complexity of subjects and phenomena, and the subsequent convergence with their reduction and simplification. The branching occur in anthropogenic World with subsequent equilibration of positive (initiated by the person) and of reciprocal negative (from the point of view of the person) branches. Binary plurality of all subjects and phenomena is characteristic for the Universe, for the Earth, nature, and for person, but simplified person's thinking is not inclined to perception of this feature of the World. Dynamical instability of development, bifurcation in a history, binary plural branching evolution of material and spiritual culture are inherent for humanity. The hierarchy and life of human community have animal sources; human qualities are binary plural. Full eradication of sins, creation of one-sided fine person, and the same society, according to the law of binary plurality, are unreal. Most common conception of Universe (doctrine about being), in our opinion, consists that the dynamical complete World consisting of binary (dual) multitude of subjects and phenomena with opposite properties; it develops with the branching growing multitude (there are examples: tree of evolution of the Universe from super-hadron to plural space; and tree of evolution of wildlife of the Earth). Branching evolution and growth of plurality cannot be infinitely: they should pass to delay, to the termination of growth, to stabilization, and to devolution of nature on the Earth. Devolution of nature on the Earth is initiated also by anthropogenic influences. Devolution in space is determined by terms of life of cosmic objects and phenomena.

\section{Basic Conception of New Philosophy}

Evolution of the Universe passes as development, growth from simple to complicated forms, similar to the treelike growth of plurality of subjects and of phenomena ("tree of growth"). Devolution of the Universe is phenomenon opposite to evolution, movement to the termination of its life, including galaxies and stars, with reduction of their luminosity, radius and temperature, with convergence and reduction of plurality. Evolution of the organic World is a process of branching development ("tree of evolution"), of growth of a variety from simple forms of life to more complex and highly organized forms, growth of multitude of mutual relation, with continuation of life of simple forms. Devolution of the organic World is process, return to evolution, with convergence of branches and reduction of bio-variety and complexity, with degeneration, with reduction of the area and destruction of nature, with disappearance of species, growth of pollution and of artificiality of environment. The form of evolution is a branching (tree), the form of devolution is a convergence; the form of life is a circle (circulation of substance); a spiral is one of forms of subjects and phenomena (from chromosomes up to galaxies) (Figure 1). According to the law of dynamical integrity, the branching development and convergence realize at varying internal unity of the World, with chain reactions of the adaptation to new integrity. Dynamical integrity of the branching and converging World is an internal conditionality of its components including binary multitude of the parties and connections with balancing properties, including oppositions.

The model of the pulsating Universe proves to be true, in opinion of the author, by conformity of a deadline of rotation of electrons in orbits of atoms (then the matter should undergo basic negative changes; it maybe in a

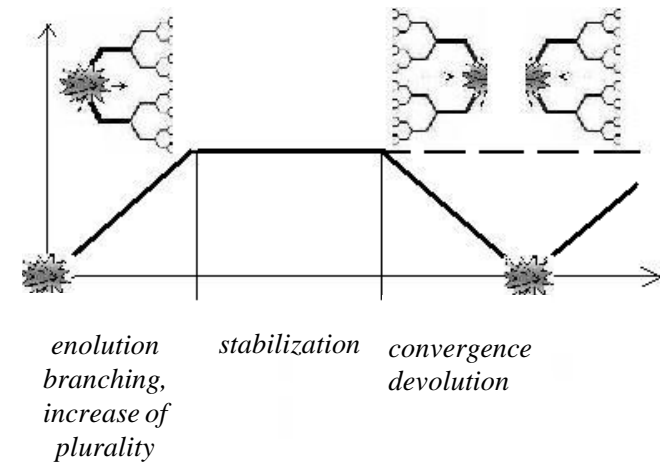

(a)

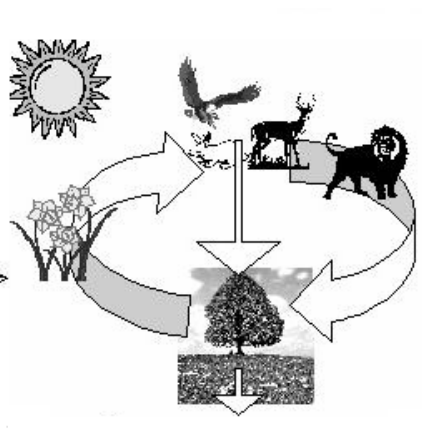

(b)

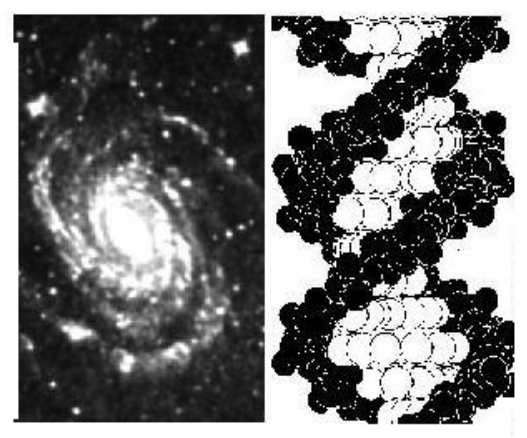

(c) (d)

Figure 1. The diagram of life of subjects (a); the diagram is real for model of the pulsating Universe, but its form is identical for all subjects; the dotted line shows a stop of devolution of nature of planet at duly intervention-ecologization, restoration of nature; circulation of substances (b), spirals of galaxies (c) and chromosomes (d). 
100 billion years) and of time from initial explosion and expansion to compression of the Universe in super-hadron. Thus, the matter essentially will not have time to change the properties because of delay of rotation of electrons. This model corresponds also to the law of branching development and of subsequent convergence, common for subjects of the World, and to a cycle as to the form of existence of subjects in the World.

Integrity of binary plural World is expressed in a dynamical combination mutually balancing of subjects and of phenomena making the general picture of integrity. It includes, for example, available "norms" of kinds of landscapes (woods, deserts, ice, bogs etc., and balancing combination of human qualities (unhealthy equilibration of genius etc.). The person does not perceive determinism of binary plurality of the World, as a rule; a person has propensity to the simplified dual and emotionally painted perception of the World, to estimation of subjects and of phenomena from two sides ("good-poorly", etc.). The reason of it that short-term memory of the person is limited on volume in view of need of fast reaction of ancestors in critical situations for guaranteeing of a survival. The simplified perception of binary plurality of the World is supported with that driving force of development of the most part of humanity is the aspiration to fast satisfaction of needs. There are features of perception of the outside World by the man: major role of triune brain, small volume of short-term memory, in which the man "lives" (exists), simplified thinking, disability to foresight of the remote consequences of the activities, aspiration to prompt satisfaction of needs, coloring of thoughts by feelings etc.). Ancient structures of person brain in many respects determine not only perception and thinking, but also evolution and devolution of the person and of nature of the Earth controlled by him (Figure 2). The anthropogenic evolution of nature initiated by the person proceeds with branching, balancing "positive" and "negative" (from the point of view of the person) branches. The nature answers on initiated by the person anthropogenic branch of development by the introduction of subsequent, independent of the person, of equilibrant branch, with possible devolution of nature.

There is one of important problems in the concept of development with branching; it is the opportunity of one-sidedly positive development of the anthropogenic World and of the person. Whether can come the good, not burdened by problems (wars, growth of artificiality of environment and life, application of the powerful weapon, lack of resources, global ecological crisis, finiteness of individual life, incurable illnesses, etc.), of full by happiness of existence of humanity? One-sidedly positive development, proceeding from the stated laws, is impossible. The beauty, expediency and multitude of other positive qualities in binary plural World are counterbalanced by opposite (negative from the point of view of the person) qualities at presence of intermediate and neutral properties of subjects and of phenomena (Figure 3). The new phenomenon in philosophy of values became "capitalization" of environment and life (estimation of all subjects and of phenomena from the point of view of their cost, their transformation into the capital). The border between material and spiritual values is moved in the material side owing to "capitalization". Spiritual values depart on a background; they can be replaced completely with material values. It conducts to replacement of spiritual perfection by material perfection.

The person created (according to simplified dual thinking) the laws of evolution based, as a rule, on dual representation (the law of negation of negation, the law of unity and conflict of opposites, the law of transition of quantitative changes in qualitative, the law of progress and regress in development, etc.). Everything that was not conformed to these laws was referred to exceptions (it is attribute of limitation of laws). Actually all rules and exceptions should enter into binary plurality. The person knows not all exceptions and rules. It emphasizes incompleteness of laws and opportunity of their inclusion as private laws in general laws, taking into account binary plurality of subjects and the phenomena and their connections. There is not in nature general form of being as contradiction, there is a multitude of forms-from harmony to struggle, including both neutral interaction, and mutual aid. Mutual relations have sometimes-difficult character, not entered in simple dual definitions (harmony, struggle). Sometimes parasites render some help to the owner, and without parasites, their organism cannot exist. The law of negation of negation not always operates: the subsequent forms can degenerate in comparison with previous, not generating the highest forms. Sometimes forms do not change, not denying themselves and not passing to the highest forms. In a field of plurality of forms of life, of existence of matter, of connections and relations, the majority of parameters accept multitude of meanings.

According to the law of binary plurality of anthropogenic World developing with balancing branching, all negative (sins, angrily, lie, egoism, disgrace, etc.) will not disappear as objective part of anthropogenic binary plurality. Unique true philosophy and unique true public formation will not be created. Not all humanity will be clever, beautiful, healthy, inclined to altruism. While the binary plural nature will be live, the person will be compelled to struggle with sins, evil.

Virtues and sins of humanity are parts of binary plurality of qualities. Sins are necessary as elements of 


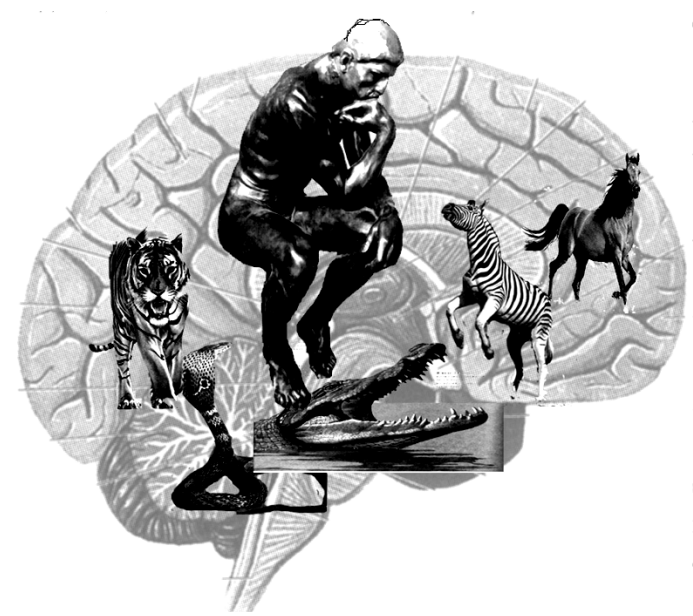

Figure 2. The trial brain of universal animal (reptile complex, limbic cortex and person cortex).

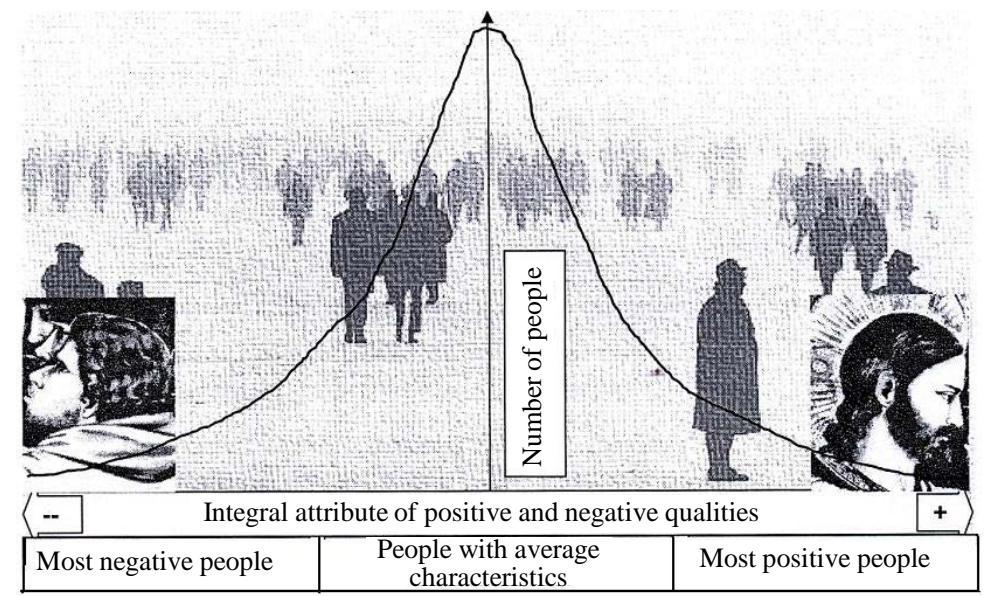

Figure 3. Gaussian distribution of integral attributes of people qualities.

mechanisms of management in nature; they are positive and negative feedbacks. The punishable sinful behavior is an example of management with a negative feedback: "sinful behavior—negative result—punishment—repentance-aspiration to virtuous behavior". Aspiration to satisfaction of multitude of positive, negative and neutral needs (from the point of view of the person) is driving force of development of humanity. New and newest needs are fixed in ancient structures of brain, in ancient "centers". The strong desire and yearning are the most ancient emotions essentially determining all human life.

The humanity exists in ineradicable binary plural space between good and evil, virtue and sins, beauty and disgrace, sense and inanity, stability and instability of development. Binary plurality reconciles with presence of real and not disappearing negative part of life, which usually is located for an opaque screen. It shows real causal-investigatory conditionality of not only positive, but also negative in the World and in the person. Taking into account above-mentioned laws, it is possible to believe: the humanity will remain as kind if a person will not find the new scientifically-technological break, whose negative result will lead to impossibility of continuation of life. The humanity should realize these laws and features of thinking to not admit it. For exception of such thinking on the major decisions of humanity, probably, introduction of expert computer systems is required, which will offer more proved ways of the decision of problems.

The role of religion as means of reasonable development of humanity grows in becoming complicated conditions of evolution of interaction of the person and of nature. Religions are based on the doctrine about integrity of the World. Some modern scientific data confirm presence of the Supreme Reason supporting integrity of the plural World. 
New physical laws of development of the Universe and of the Earth, new fundamental representations about matter, new physical constants come to light; this constant scientific progress demands from the person of the duly analysis and actions. The World up to the end is not cognizable and never will be up to the end cognizable.

Therefore, extreme care (caution) is necessary at intervention of the person in nature. At the same time, it is necessary for humanity to pay special attention to problem of modern and future devolution of the Earth and of the Universe: probably, it is impossible to encourage devolution on the Earth by replacement of nature, growth of artificiality of environment and life, disappearance of species, etc. It is necessary to investigate processes of devolution of Earth, solar system, near and distant space to reveal directions of devolution and reciprocal actions of humanity with the purpose of its preservation together with nature of the Earth. The philosophy of binary plurality of the World with its branching evolution and converging devolution promotes an explanation of opportunity of more objective interaction of the person with the World.

\section{Basic Conception of New Ethics of Empathy}

Author proposes to inculcate new ethics of empathy to life of nature, of understanding (from position of human life) all complexity and difficulty of life of animate organisms in nature. The empathy to life of divine creations of nature is empathy to life of worm, one-day moth, ant, gazelle, mollusk, plankton, wolf in snow-clad forest, "terrible" spider, etc. These billions animate creatures constantly, expediently for cycle of matter, for support of life and homeostasis on Planet, are called into being absolutely irrespective of their wish and constantly disappear. They realize small or large functions, equally irreplaceable and consequently extremely valuable for nature. Nobody will realize these functions. Life of set of animals in soil-vegetative layer is especially unenviable (from human point of view); they process all organic waste and separate them on elements again to include in cycle of matter these elements. These small animals carry out completely exclusive on value and "divine" functions; they pretend not on any understanding or sympathy on the side of somebody. Thus, they are very ugly from the point of view of person; they eat badly smelling carrion, are hidden in ground and try to not be shown on eyes.

What is life of many animals from position of human values? Life of large animals includes constant search of food, alarm for itself and for animal's young, and struggle for their growth and preservation, pain from their losses. These animals are exposed constantly to all climatic influences: rain, cold, heat, snow, drought, etc. They live or directly on nature, or arrange elementary dens, nests, shelters. Thus they hope for protection against climatic influences only with the help of own skin. Sometimes they do not sleep almost (for example, giraffes) to not become a victim of a predator. They are exposed to many illnesses, and choose a way of treatment. They have no place for treatment, except for the nature.

Small animals, including insects, worms etc., occupy the ecological niches in huge network of life, and realize the own individual functions. They cannot realize other functions, cannot be cleverer, and cannot evolve fast in the side of growth of beauty. In this connection it is possible to consider life of the various parasites living inside a body of animals and, as a rule, extremely unattractive by sight (words worm, parasite, etc. are abusive language). The parasites cannot become humane and nice; vampires and predators cannot turn to vegetative feed: they have short bowels, digesting only blood and flesh. At last, such small creations, as bacteria, microbes, viruses, also are in global network of life, and without them life of animate nature and evolution are impossible. In ethics of empathy the love to all creations of the animate nature is not required, and the more so reverence before all forms of life; it is necessary the simple understanding of their indispensability and necessity. Their life is necessary and is invaluable for nature; other animals cannot replace them. It is impossible to create for them others, more favorable, sparing conditions of life.

New ecological ethics of empathy differs from other ethics that it is more objective and dialectical. Sympathy and empathy are deep feelings based on understanding of other forms of life, their applicability and difficulties. This ethics supposes deep penetration into laws of ecology, in interrelation of all phenomena, in interdependence all animate nature and in dependence of the person from nature. It supposes knowledge of ecology, evolution, and understanding of important role of all animate nature in support of life on the Earth. Animals during evolution have occupied various ecological niches, have achieved different level of development and complicated, and very primitive. Each of them carries out a number of functions, which not anybody can carry out. We do not know, whether receive all animals any encouragement or satisfaction from life, from good realization of functions, from achievement of purpose (similarly to the man). Probably, many larger animals receive satisfaction; they are capable to game, curiosity, even to a joke. However, many simpler animals are hardly capable to receive any encouragement for the action. The life of all animals proceeds in complex conditions: they depend 
very much on weather and features of a climate, from a status of an environment, from features of mutual relation in that food chain, in which they are. Many little animals perish, not having achieved maturity. Many animals perish after birth of posterity. Some animals perish during pairing. The huge mass of animals realizes functions of sanitation of the nature, clearing it from waste. Many animals are food for other animals. The person is able to understand only such dangerous, heavy, complete hardship life of animals. They of anything were not guilty; they realize very important functions frequently in awful conditions from the human point of view. They help to support life on the Earth. The ethics of empathy will help the person to concern to animate nature more objectively.

\section{Conclusion}

New philosophy of binary plurality of branching and converging World offers comprehension of binary plurality branching and then converging Universe, binary plurality of life, of nature, of society, of person, culture, engineering, needs, etc., at dynamical internal unity of the World, with chain reactions by adaptation to new complicated (at evolution) or to simplified (at devolution) integrity. The World, probably, conforms to the laws of binary plurality of the nature, of branching and converging development (not admitting one-sided development, with equilibration of branches), of dynamical integrity of nature (varying internal unity of the World with constant chain reactions of the adaptation to new integrity). The humanity exists in ineradicable binary plural space between good and evil, virtue and sins, beauty and disgrace, sense and inanity, stability and instability of development. Binary plurality explains real cause-effect conditionality not only positive, but also negative in the World and in the person. Comprehension of binary plurality of the World is important for humanity: the person must understand the binary plural nature, its branching development and convergence, "soft" adaptive interaction with nature, "soft" flexible reaction, preservation of the most part of nature of the Earth, of biovariety, landscapes, resources, conditions of natural evolution. The person should understand integrity of binary plural branching and converging World for the well-founded interaction with World, with ecologization for the termination of devolution, for preservations of nature and humanity, for definition of the future together with the future of the Earth. It is necessary to inculcate ecological ethics of interaction with nature and new ethics of empathy.

\section{References}

[1] (1983) Philosophical Encyclopedic Dictionary. SE, Moscow, 840 p.

[2] Tetior, A. (2013) New Philosophy of Binary Plurality of the Branching and Converging World. Palmarium, 698 p.

[3] Tetior, A. (2010) Concept of Development of Humanity. Rior, Moscow, 200 p.

[4] Tetior, A. (2000) Plurality of Environmental Ethics. Nature, Moscow, 63 p. 